\title{
COMPREENSÃO DOS ENFERMEIROS SOBRE O EXERCÍCIO DA LIDERANÇA NO AMBIENTE HOSPITALAR*
}

Simone Coelho Amestoy, Vânia Marli Schubert Backes², Letícia de Lima Trindade³, Veridiana Corrêa Ávila Anelise Freitas Lins de Oliveira ${ }^{4}$, Camila Neves da Silva ${ }^{5}$

${ }^{1}$ Enfermeira. Doutora em Enfermagem. Universidade Federal de Pelotas. Pelotas-RS-Brasil.

${ }^{2}$ Enfermeira. Doutora em Enfermagem. Universidade Federal de Santa Catarina. Florianópolis-SC-Brasil.

${ }^{3}$ Enfermeira. Doutora em Enfermagem. Universidade do Estado de Santa Catarina. Chapecó-SC-Brasil.

${ }^{4}$ Enfermeira. Mestranda em Enfermagem. Universidade Federal de Pelotas. Pelotas-RS-Brasil.

${ }^{5}$ Acadêmica de Enfermagem. Universidade Federal de Pelotas. Pelotas-RS-Brasil.

RESUMO: Objetivou-se conhecer a compreensão dos enfermeiros sobre liderança, bem como as estratégias utilizadas que facilitam seu exercício no ambiente hospitalar. Trata-se de uma pesquisa de abordagem qualitativa do tipo descritiva, na qual foi usado o estudo de caso como estratégia de investigação. Participaram 25 enfermeiros que trabalham em hospitais de Florianópolis-SC-Brasil. As informações foram obtidas de maio a dezembro de 2010, por meio de entrevistas semiestruturada e oficinas dialógicas, e analisadas por meio da Análise Temática, emergindo dois temas: Compreensão dos enfermeiros sobre liderança e Estratégias que facilitam o exercício da liderança. Os resultados sinalizam que a liderança é uma habilidade relacional que contribui para o gerenciamento do cuidado, da equipe e do ambiente hospitalar, sendo potencializada pelo diálogo enquanto principal estratégia que facilita e fortalece o exercício da liderança do enfermeiro.

DESCRITORES: Enfermagem; Liderança; Hospitais.

\section{NURSES' UNDERSTANDING OF THE EXERCISING OF LEADERSHIP IN THE HOSPITAL ENVIRONMENT}

\begin{abstract}
This study aimed to investigate nurses' understanding regarding leadership, as well as the strategies used for facilitating its exercising in the hospital environment. It is research with a qualitative approach of the descriptive type, in which the case study was used as the investigative strategy. The participants were 25 nurses who worked in hospitals in Florianópolis, in the Brazilian state of Santa Catarina. The information were obtained between May and December 2010, through semi-structured interviews and dialogic workshops, and were analyzed using Thematic Analysis, with two themes emerging: 'The nurses' understanding regarding leadership', and 'Strategies which facilitate the exercising of leadership'. The results indicate that leadership is a relational skill which contributes to the management of the care, the team, and the hospital environment, being strengthened by dialogue as the main strategy facilitating and strengthening the exercising of the nurse's leadership. DESCRIPTORS: Nursing; Leadership; Hospitals.
\end{abstract}

\section{COMPRENSIÓN DE LOS ENFERMEROS SOBRE EL EJERCICIO DEL LIDERAZGO EN EL AMBIENTE HOSPITALAR}

RESUMEN: Se objetivó conocer la comprensión de los enfermeros sobre liderazgo, así como las estrategias utilizadas que facilitan su ejercicio en el ambiente hospitalar. Se trata de una investigación de abordaje cualitativo del tipo descriptivo, en la cual fue usado el estudio de caso como estrategia de investigación. Participaron 25 enfermeros que trabajan en hospitales de Florianópolis, SC, Brasil. Las informaciones fueron obtenidas de mayo a diciembre de 2010, por medio de entrevistas semiestructuradas y oficinas dialógicas, y analizadas por medio del Análisis Temático, resultando en dos temas: Comprensión de los enfermeros sobre liderazgo y Estrategias que facilitan el ejercicio de liderazgo. Los resultados apuntan que el liderazgo es una habilidad relacional que contribuyó para la gestión del cuidado, del equipo y del ambiente hospitalar, siendo potencializada por el diálogo como principal estrategia que facilita y fortalece el ejrcicio del liderazgo del enfermero.

DESCRIPTORES: Enfermería; Liderazgo; Hospitales.

\footnotetext{
*Artigo original, desenvolvido a partir da tese de doutorado Liderança dialógica: perspectivas na formação de enfermeiros-líderes, apresentada ao Programa de Pós-Graduação da Universidade Federal de Santa Catarina, 2012.
} 


\section{INTRODUÇÃO}

Trabalhar e intervir nos cenários de produção de cuidado nos serviços de saúde são tarefas consideradas complexas. Vive-se em um momento em que a saúde é tratada como questão de primeira importância para a população, levando gestores e trabalhadores a elaborar e implantar políticas públicas das mais diversas ordens: de gestão, de assistência, de educação e pesquisa, clamando aos profissionais de saúde a atuar ativamente frente às necessidades de saúde da população ${ }^{(1)}$.

No contexto da saúde, a Enfermagem é a ciência do cuidar e organiza-se como sendo um trabalho coletivo e em colaboração com outros profissionais e trabalhadores do campo da saúde. Baseia-se em um saber consolidado que deve disponibilizar bases para a prática, subsidiar a construção de caminhos para o enfrentamento de novos e velhos problemas do campo da saúde e específicos ao seu núcleo profissional. Os desafios enfrentados pela enfermagem demandam mudanças no perfil demográfico, epidemiológico da população e pela complexidade inerente ao processo de cuidar das pessoas com necessidades de saúde ${ }^{(2)}$.

Para tanto, torna-se relevante que o enfermeiro apresente a capacidade de liderar, sendo este um fator importante para que esse profissional consiga conduzir sua equipe e facilitar o trabalho e a assistência prestada ao usuário. Porém, o exercício da liderança da enfermagem é considerado um grande desafio vivenciado pelos enfermeiros nos serviços de saúde, em especial nas instituições hospitalares, uma vez que são organizações complexas que absorvem grande parte dos profissionais de saúde e por este motivo, é comum o enfrentamento de situações conflitantes $^{(3)}$. Para este estudo, a liderança consiste em uma competência profissional do enfermeiro, que representa a capacidade em influenciar as pessoas, por meio do diálogo, com o objetivo de alcançar as metas estabelecidas pelo grupo, que no caso da enfermagem, reportase ao cuidado ao ser humano(4).

Ao analisar a produção científica a respeito da liderança, identificou-se que o interesse sobre o tema vem crescendo nos últimos anos envolvendo a liderança do enfermeiro no ambiente hospitalar, buscando entender as particularidades para liderar neste cenário. Dentre estes destacam-se estudos que investigaram o tema em unidade de cuidados $\operatorname{críticos}^{(5)}$, as expectativas da equipe de enfermagem em relação à liderança do enfermeiro ${ }^{(6)}$ e a ênfase na utilização do diálogo, enquanto recurso que auxilia o exercício da liderança nas instituições hospitalares $^{(7)}$. Também já se buscou identificar os desafios que os enfermeiros recém-formados enfrentam para liderar ${ }^{(8)}$. Outros desvelaram o ensino da liderança, tanto abordando a visão dos docentes de enfermagem ${ }^{(9)}$, como a percepção do processo de ensino-aprendizado da liderança para os próprios enfermeiros ${ }^{(10)}$.

Mesmo estando em evidência estudos sobre o tema, o mesmo ainda carece de investigações, pois é possível identificar que o enfermeiro possui dificuldades para exercer a liderança ${ }^{(8,11)}$ e no contexto de saúde atual necessita-se, cada vez mais, de enfermeiros-líderes competentes técnico-cientificamente e capazes de gerenciar o cuidado e a equipe de enfermagem, utilizandose o diálogo, a ética e a humanização(10). Em virtude dos resultados destas pesquisas, tornase relevante continuar abordando a liderança junto aos enfermeiros, para que os mesmos possam esclarecer melhor seu entendimento sobre esta competência profissional e otimizar seu exercício na prática. Diante disso, o presente estudo tem por objetivo conhecer a compreensão dos enfermeiros sobre liderança, bem como as estratégias utilizadas que facilitam seu exercício no ambiente hospitalar.

\section{MÉTODO}

Estudo de abordagem qualitativa do tipo descritiva, em que foi utilizado o estudo de caso como estratégia de investigação. Participaram do estudo 25 enfermeiros que trabalhavam em três hospitais gerais da cidade de Florianópolis-SC-Brasil, que demonstraram interesse em discutir e refletir sobre liderança na enfermagem. Foram convidados para participar do estudo, enfermeiros que possuíam até seis anos de formação. Escolheu-se este período, a fim de contemplar aqueles formados segundo as diretrizes curriculares nacionais, que considera o estudo do desenvolvimento de competências.

Optou-se em realizar a pesquisa nestes locais por se tratarem de hospitais de destaque em termos de assistência à saúde na cidade de Florianópolis. Além disso, pretendeu-se identificar 
a existência ou não de dissonâncias na prática da liderança do enfermeiro, em virtude de possuírem administrações diferentes, ou seja, federal, filantrópico e estadual.

Utilizaram-se entrevistas semiestruturadas como técnicas para coleta dos dados. As entrevistas foram realizadas no próprio local do estudo, com data e hora pré-estabelecida, conforme contato prévio com os participantes. Foi utilizado um roteiro criado pelas pesquisadoras para nortear a coleta, buscando questionar os participantes sobre o entendimento que possuíam a respeito da liderança, como tem sido para eles coordenar uma equipe, os desafios que enfrentavam para liderar no ambiente hospitalar e as estratégias que poderiam ser implementadas para facilitar o exercício da liderança. As entrevistas foram gravadas e transcritas logo após seu término. Os depoimentos de cada participante foram identificados pelas letras $\mathrm{E}$ de entrevista e o número ordinal correspondente a sua realização com os enfermeiros (E1, E2... E25).

Após a etapa de entrevistas foram realizadas três oficinas, uma em cada hospital, as mesmas tiveram como objetivo estimular a reflexão e promover a discussão sobre a liderança, bem como proporcionar o debate coletivo sobre a formação de enfermeiros-líderes e o desenvolvimento permanente do enfermeiro nas instituições hospitalares. Informa-se que os enfermeiros participaram das oficinas realizadas no hospital em que trabalhavam, não foi possível realizar uma oficina contando com a participação de todos os sujeitos do estudo em um mesmo local, mediante dificuldades encontradas para reuní-los.

Todas as oficinas seguiram a mesma dinâmica. Primeiramente, o grupo foi instigado a pensar sobre "o que é liderança?". Formaram-se duplas, com o intuito de realizar uma pequena discussão, após as duplas expuseram ao grupo os significados que atribuíram à liderança. Depois, apresentou-se um vídeo que abordava a importância da liderança, com a finalidade de descontrair o grupo e relacionar algumas questões do vídeo com a prática dos enfermeiros. Durante as oficinas dialógicas, também se realizou uma dinâmica envolvendo a leitura aleatória de frases escolhidas previamente pela pesquisadora, que possuíssem ligação com a temática liderança. Cada participante escolheu um envelope colorido contendo uma frase, após faziam a leitura individual e eram destinados cinco minutos para reflexão, depois se realizou a leitura da frase para o grupo, a apresentação da reflexão de cada participante e por fim, a colaboração do grupo com suas reflexões.

Cada oficina dialógica durou em média 1 hora e 30 minutos, as mesmas foram gravadas em áudio. Os depoimentos advindos das oficinas dialógicas foram identificados com as letras OD, mais o número ordinal representando cada enfermeiro (OD1, OD2... OD25). Uma das pesquisadoras exerceu o papel de moderadora dos encontros. As informações foram obtidas de maio a dezembro de 2010.

Com o intuito de analisar os dados utilizouse Análise Temática, que se caracteriza por dois momentos operacionais. O primeiro inclui as determinações fundamentais do estudo, o qual é mapeado na fase exploratória da investigação. E o segundo momento denomina-se de interpretativo, pois consiste no ponto de partida e no ponto de chegada de qualquer investigação, representa o encontro com os fatos empíricos. A fase interpretativa apresenta duas etapas: a ordenação dos dados e a classificação dos dados, que inclui a leitura horizontal e exaustiva dos textos, leitura transversal, análise final e a construção do relatório com a apresentação dos resultados ${ }^{(12)}$.

Foram respeitados os princípios éticos estabelecidos pelo Conselho Nacional de Saúde do Ministério da Saúde, a qual estava em vigor no período de apresentação do projeto ao Comitê de Ética em Pesquisa da Universidade Federal de Santa Catarina, sendo aprovado sob o Protocolo n. 658/10.

\section{RESULTADOS}

Os resultados foram organizados em duas categorias, denominadas: Compreensão dos enfermeiros sobre liderança e Estratégias que facilitam o exercício da liderança.

\section{Compreensão dos enfermeiros sobre liderança}

Ao buscar conhecer a compreensão dos enfermeiros sobre o tema, verificou-se que o líder é compreendido como a pessoa que é o exemplo para a equipe, dando suporte, segurança e apoio, em busca do mesmo objetivo, ou seja, 
a qualidade da assistência.

Liderança pra mim eu acho que é um ponto de referência sabe, ser um porto seguro ali, onde elas sabem que podem encontrar repostas, encontrar apoio, compreensão, acho que ser líder é isso. Conseguir agir com amor e com competência ao mesmo tempo. Acho que isso é um bom líder, uma pessoa de referência que as pessoas possam confiar. (E5)

Acho que a liderança de um modo geral ela dá apoio, ela orienta e ela supervisiona o cuidado, relacionamento, tudo, todo processo. É eu me vejo com essas responsabilidades quanto à minha equipe, e eu das minhas lideranças busco a mesma coisa, que é: suporte, orientação e dar o retorno do que foi feito, é acompanhar resultados. (E6)

Eu acho que liderança é exemplo, é espelho, é o farol, é o que distribui as tarefas, é querer melhorar a unidade, facilitar o trabalho de todo mundo, porque eu acho também que a gente facilitando o nosso trabalho tu vai melhorar os pacientes, a gente vai ter mais tempo, mais dedicação pra atendê-los. (OD23)

Além disso, de acordo os depoimentos a seguir verifica-se a importância de o líder cooperar e trabalhar em conjunto com a equipe, sendo uma referência, com o intuito de alcançar objetivos em comum, que no caso do exercício da liderança no ambiente hospitalar refere-se ao cuidado ao paciente.

O líder é a pessoa responsável por coordenar certas atividades em determinado tempo para que um objetivo seja alcançado. No nosso caso o objetivo é uma assistência de qualidade ao paciente, essa questão assim. (OD10)

[...] liderar não é mandar e fazer o outro se submeter sempre a ti, é bem pelo contrário, trabalhar em equipe, saber conversar com a pessoa, tu saber interagir com ela de uma forma que ela queira seguir o que tu tá propondo e não tu ter que impor a tua idéia em cima dos teus colaboradores, então eu procuro agir assim, com consenso. (E21)
Bom, eu acho que o líder é aquela pessoa em que todos da tua equipe. Ai como que eu posso dizer? É aquela pessoa que está sempre ali pronta. Todos que estão ao redor buscam a ela. Não buscam outros meios e sim vão direto a ela. Eu acho que o líder deve ser parceiro. (E25)

Também se pode identificar o autoritarismo como uma fragilidade no exercício da liderança do enfermeiro, devendo ser evitado no ambiente hospitalar.

Quando você está chegando a um setor como enfermeiro você vai exercer uma hierarquia, existem diferente niveis de tomadas de decisão, então está todo mundo com o pé atrás. Então você vai ter de alguma forma que conquistar o seu espaço. Ter que disputar mesmo. Não adianta. E se chegar como autoritária vai ser pior ainda, vai bater de frente com todo mundo. (OD11)

Outro resultado relevante foi o gerenciamento de conflitos, considerado como uma atividade presente no trabalho dos enfermeiros nas três instituições investigadas, ocasionada principalmente por problemas no relacionamento interpessoal entre os membros da equipe de enfermagem.

Já houve conflitos sim, às vezes, são coisas tão tolas que prefiro nem dar ouvidos. Só digo para eles vocês vão trabalhar juntos então, não vão querer trabalhar num clima ruim, então precisam se entender. Geralmente o que dá mais problema é fofoquinha de um falando do outro, isso é o maior perigo, em qualquer unidade. (E19)

Acho que relação interpessoal é bem mais difícil, porque se é só problema na técnica tu vai e fala, agora a relação interpessoal é complicada para gerenciar. (E4)

\section{Estratégias que facilitam o exercício da liderança}

Diante dos resultados obtidos destaca-se a imparcialidade como uma estratégia que auxilia o enfermeiro a exercer a liderança no ambiente hospitalar. 
Ser imparcial, eu acho que primeiramente ser imparcial. Porque é óbvio que na equipe tu tens integrantes com quem tu tens mais afinidade pessoal, mas tu não pode deixar isso no momento de tomada de decisão interferir na tua conduta como líder. Tens que ser imparcial. (OD 4)

Saber ouvir foi outra estratégia que emergiu neste estudo podendo ser evidenciada no seguinte depoimento:

Cada um tem um ponto de vista, cada um tem uma maneira de ver as coisas e também as atitudes da gente, tu consegues, se tu ouvir, alguns acham, tu toma uma atitude e cada um tem uma visão diferente daquilo que tu fez. Alguns acham que 'não, não deveria ter feito', outros, 'não, acho que tu fez certo'. Então é aquela coisa, tu precisa ouvir realmente a tua equipe até pra ti melhorar, pra ti explicar, ver bem as coisas. Eu acredito que seja isso. (OD 11)

O diálogo foi compreendido como principal estratégia utilizada pelos enfermeiros durante o exercício da liderança.

Eu acho que o diálogo é a principal, como fazer as coisas conversando tanto com o paciente como quem cuida dele. Eu acho que isso é importante assim, desenvolver uma liderança com base no diálogo, na conversa, acho que isso é primordial pra satisfação de todos. (E5)

Pra mim tudo é conversar. Combinar vamos fazer desse jeito, eu acho que pode ser melhor se a gente fizer assim, aceitar a opinião da equipe também, [...] tem que ter um consenso entre todos. (E21)

Baseio meio trabalho no diálogo, eu prezo muito a conversa. (E24)

Eu acho que todas nós batemos nas mesmas teclas, da comunicação e do diálogo na liderança, porque eu acho que o desafio maior é mostrar pra eles, o porquê que eles estão fazendo e eles compreenderem a importância daquilo que estão fazendo. (OD10)

\section{DISCUSSÃO}

O papel de líder requer uma visão ampla e sistêmica das diversas situações que enfrenta em seu processo de trabalho, por isso o enfermeiro deve se preparar, inovar e buscar novas formas para o exercício da liderança, visto que a maneira como esse profissional conduz a equipe influencia diretamente em um sistema de cuidado comprometido, ou não, com as necessidades das pessoas $^{(13)}$. Assim, percebe-se que a liderança representa uma atividade relacional que está intimamente associada à enfermagem, visto que o enfermeiro necessita coordenar, prestar apoio e motivar sua equipe e devido a essas características é capaz de influenciar diretamente as ações da equipe de enfermagem e multidisciplinar.

Reconhecer e apropriar-se de um lugar, bem como utilizá-lo para otimizar as lideranças dentro das equipes de trabalho, é uma escolha sensata que pode representar um grande avanço para a profissão e qualificação das ações de saúde. Ao incentivar as práticas de liderança compartilhada nas equipes, pode-se promover o desenvolvimento de formas mais cooperativas e integradas de trabalho ${ }^{(14)}$.

O entendimento de liderança está relacionado à preocupação com o cuidado do ser humano com carências de saúde, contemplando, ainda, a gestão da unidade e as necessidades dos trabalhadores da equipe ${ }^{(15)}$. Assim, liderar constitui-se na capacidade do líder de conduzir e organizar o trabalho da equipe com o objetivo de disponibilizar um atendimento eficiente, utilizando-se para isso conhecimentos técnicocientíficos e o domínio de habilidades humanas e interpessoais ${ }^{(16)}$. Por isso, somente pode ser líder de uma equipe a pessoa que promove autoconhecimento, traça metas estratégicas para seu crescimento pessoal e profissional, bem como de seus colaboradores, visando fortalecer as potencialidades do grupo e superar suas próprias fragilidades ${ }^{(17)}$.

Neste sentido, o líder representa o elo de apoio para a equipe, tanto no que se refere à educação como a coordenação do serviço, pois tem a responsabilidade de estimular o desenvolvimento do potencial coletivo, o que irá interferir diretamente na qualidade da assistência ${ }^{(6)}$. 
Em face do processo de trabalho da enfermagem, torna-se importante resgatar que o enfermeiro, exercendo o papel de líder, tem seu foco na tarefa profissional, ou seja, no cuidado das pessoas que necessitam da assistência de enfermagem ${ }^{(5,18)}$. Assumir o cuidado significa ser responsável por articular os diferentes profissionais, em um trabalho em equipe, interdisciplinar, colaborativo e horizontal, buscando assistir o sujeito do cuidado em sua integralidade, com necessidades a serem atendidas e ainda, com desejos, emoções, impregnado de objetividade e subjetividade(5).

Os depoimentos evidenciaram a compreensão dos enfermeiros a respeito do papel do líder, demonstrando que dependendo da forma como esse papel é desempenhado, ele pode acarretar prejuízos ao coletivo. Nesse sentido, o líder autoritário se posiciona no topo da hierarquia, centralizando o poder de decisão, podendo desfrutar do prestígio, status e estabilidade social, resultantes da sua administração, bem como responder sozinho pelo insucesso de suas ações $^{(19)}$. O autoritarismo distorce a liderança, tornando-a um instrumento de demonstração de poder e dominação, por este motivo, almeja-se preservar estilos de liderança que potencializem o estabelecimento de relações saudáveis no ambiente hospitalar, que possam contribuir efetivamente com a condução da equipe de saúde e de enfermagem repercutindo na qualidade do cuidado prestado. Os depoimentos dos enfermeiros retomam a importância e centralidade do líder para equipe e a preocupação com os limites do poder exercido sobre a equipe, demonstrando preocupação com as relações tecidas na condução da liderança.

Além disso, os enfermeiros destacaram o gerenciamento de conflitos como uma atividade vivenciada no ambiente de trabalho, ocasionada principalmente por problemas nos relacionamentos interpessoais. Caso não sejam gerenciados de forma adequada, podem causar maiores desconfortos entre os membros da equipe, prejudicando o clima de trabalho e até mesmo interferindo na assistência prestada.

Estudo realizado com profissionais da área da saúde indica que a liderança costuma ser associada a um papel afetivo e compreensivo do líder, enquanto o chefe está limitado ao comando e ao controle. Neste sentido, possivelmente, as relações hierárquicas são conflituosas, porque as pessoas que atuam em cargos de comando são consideradas pejorativamente como chefes. Em contrapartida, também é possível apontar uma postura de expectador por parte das pessoas que se consideram subordinado, uma vez que esperam que o líder resolva todos os problemas, não havendo corresponsabilidade, reforçando a adoção de uma postura passiva ${ }^{(3)}$.

Por isso, cabe reforçar que o trabalho em enfermagem é desenvolvido em equipe, assim, espera-se que o enfermeiro perceba a importância do processo de liderança como um aprendizado contínuo e dinâmico, e seja capaz de guiar as pessoas para que trabalhem entusiasmadas, a fim de atingirem os objetivos em comum $^{(6)}$. Para isso, o líder deve ser parceiro de sua equipe, auxiliá-la e esforçar-se para ser reflexo de um bom profissional, comprometido com suas responsabilidades e com seu papel na organização, além de estimular o comprometimento, a participação e a co-responsabilização de todos na tomada de decisões.

Cabe reforçar que o enfermeiro, enquanto líder e profissional de referência nos serviços de saúde, em virtude da gama de atividades que desenvolve, precisa colaborar com o fortalecimento do hospital como um ponto de atenção da rede, contribuindo com sua organização de forma regionalizada, articulada e integrada, possuindo gestão participativa, transparente e democrática, buscando preservar acima de tudo a segurança do paciente. Frente ao exposto, reforça-se a necessidade de estimular a formação de enfermeiros com potencial para assumir posições de liderança nos serviços de saúde, em especial, no ambiente hospitalar, em virtude da complexidade do atendimento dispensando neste nível de atenção.

Quanto às estratégias utilizadas para facilitar o exercício da liderança, destacam-se nos depoimentos dos sujeitos deste estudo: imparcialidade, saber ouvir e o diálogo. A imparcialidade na tomada de decisões é essencial no trabalho do enfermeiro. Assim, o enfermeirolíder necessita agir com racionalidade e evitar tomar uma decisão com base unicamente na intuição e sem analisar todas as dimensões que permeiam uma situação conflitante, bem como precisa saber ouvir cada integrante da equipe. Fala-se aqui de um ouvir atento, que 
valorize verdadeiramente a opinião de todos os profissionais, atuando como colaboradores neste processo de fazer saúde. Assim, pode-se dizer que estas duas estratégias estão interrelacionadas, pois colaboram para tomada de decisão e gerenciamento de conflitos, amparando de forma segura e responsável a liderança do enfermeiro.

Identificou-se o diálogo como principal estratégia, por meio da comunicação (conversa) o enfermeiro busca assegurar no seu processo de trabalho a resolução dos conflitos, iniciativa nas tomadas de decisões, e gera um vínculo profissional saudável entre a equipe. Outros estudos também enfatizam o diálogo/comunicação como estratégias que facilitam o exercício da liderança $\mathrm{a}^{(7-8)}$.

Em conformidade com os achados deste estudo, defende-se uma nova proposta de liderança, sustentada no diálogo, que pode contribuir para a construção da prática de relações mais emancipatórias autônomas e dialógicas entre profissionais de saúde no ambiente hospitalar ${ }^{(11)}$.

Desta forma, destaca-se a liderança dialógica, sendo considerada como a capacidade do líder de influenciar seus colaboradores a atuarem de maneira crítica e reflexiva sobre sua práxis, mediante o estabelecimento de um processo comunicacional eficiente ${ }^{(11)}$, diante disso o diálogo entre colegas e chefias é apontado como uma maneira de promover a humanização no ambiente de trabalho ${ }^{(20)}$.

A liderança dialógica também pode ser entendida como ato político, que pode ser utilizada como estratégia pelo enfermeiro-líder em seu ambiente de trabalho, a fim de nortear seu estilo de liderança, pois ao ser considerado um ser relacional e singular, o homem diferencia-se dos demais mediante a defesa de suas convicções em seu contexto social, além disso, tornar-se-á possível a construção de novas formas de atuar na área da saúde, a partir da adoção de posturas mais democráticas, humanas e éticas, as quais potencializam a liberdade de expressão dos trabalhadores, buscando superar as relações de poder baseadas no autoritarismo e na opressão ${ }^{(10)}$.

Compreende-se que as vantagens oportunizadas pela liderança dialógica são para que o enfermeiro se baseie no estabelecimento de um processo comunicacional eficiente, a fim de estimular a autonomia, a co-responsabilização e a valorização de sua equipe e dos usuários dos serviços hospitalares, assim como auxiliá-lo na tomada de decisões, no planejamento e na implementação das práticas assistenciais ${ }^{(11)}$.

Contudo, isso requer a construção de vínculos importantes entre os profissionais, o que se mostra um dos principais desafios para promoção da articulação teoria e prática. Frequentemente a fragilidade desse vínculo impede a construção de ações que favoreçam a qualidade na assistência, realmente conscientes e capazes de intervir sobre a realidade, especialmente no Sistema Único de Saúde (SUS), assim como permitam que os serviços utilizem das inovações e conhecimentos $^{(9)}$.

\section{CONCLUSÕES}

Este estudo possibilitou conhecer a compreensão dos enfermeiros sobre liderança, bem como as estratégias utilizadas que facilitam seu exercício no ambiente hospitalar. Os participantes enfatizam a adesão na prática por uma liderança pautada no diálogo, que representa na capacidade do líder de influenciar seus colaboradores a atuarem de maneira crítica e reflexiva, por meio de relações horizontais no ambiente de trabalho, nas quais florescem oportunidades de trocas de conhecimentos e aprimoramento coletivo entre o líder e seus colaboradores, bem como há espaço para a autonomia e participação ativa de enfermeiros, equipe e usuários, enquanto atores sociais.

O ambiente hospitalar consiste em um serviço de alta complexidade, que necessita da aderência de seus gerentes às condutas democráticas e horizontais, a fim de atender as demandas de saúde da população. Para tanto, o enfermeiro exerce papel fundamental na organização do serviço. O diálogo é a principal estratégia que facilita o exercício da liderança no ambiente hospitalar, a fim de disponibilizar um cuidado de qualidade.

Salienta-se que independente da instituição hospitalar, os enfermeiros apresentaram dificuldades semelhantes em se posicionar frente à equipe de enfermagem e gerenciamento de conflitos, mas em sua maioria, utilizam o diálogo para nortear os desafios enfrentados no ambiente hospitalar. 
Sabe-se que o tema liderança é bastante investigado na área, no entanto, reforça-se a necessidade de estudos nesta vertente, para que seja possível fortalecer as ações do enfermeiro ao desempenhar o gerenciamento do cuidado, enquanto referência da equipe de enfermagem e da equipe de saúde no ambiente hospitalar, bem como frente aos desafios crescentes na atuação gerencial desse profissional.

\section{REFERÊNCIAS}

1. Menegaz JC, Backes VMS, Amestoy SC. Formação política para fortalecimento de liderança em enfermagem: um relato sobre a experiência. Enfer. Foco. 2012;3(4):190-3.

2. Pires DEP. Transformações necessárias para o avanço da Enfermagem como ciência do cuidar. Rev. bras. enferm. 2013;66(n.esp):39-44.

3. Vendemiatti $M$, Siqueira ES, Filardi F, Binotto E, Flávio JS. Conflito na gestão hospitalar: o papel da liderança. Ciênc. saúde colet. 2010;15(1):1301-14.

4. Amestoy SC. Liderança dialógica: perspectivas na formação de enfermeiros-líderes. 2012. [tese]. Florianópolis (SC): Universidade Federal de Santa Catarina; 2012.

5. Gelbcke FL, Souza LA, Sasso GMD, Nascimento E, Bulb MBC. Liderança em ambientes de cuidados críticos: reflexões e desafios à Enfermagem Brasileira. Rev. bras. enferm. 2009;62(1):136-9.

6. Moura GMSS, Inchaupe JAF, Dall'agnol CM, Magalhães AMM, Hoffmeister LV. Expectativas da equipe de enfermagem em relação à liderança. Acta Paul. Enferm. 2013;26(2):198-204.

7. Amestoy SC, Trindade LL, Waterkemper R, Heidmanl ITS, Boehs IAE, Backes VMS. Liderança dialógica nas instituições hospitalares Rev. bras. enferm. 2010;63(5):844-7.

8. Vilela PF, Souza AC. Liderança: um desafio para o enfermeiro recém-formado. Rev. enferm. UERJ. 2010;18(4):591-7.

9. Ávila VC, Amestoy SC, Porto AR, Thofehrn MB, Trindade LL, Figueira AB. Visão dos docentes de enfermagem sobre a formação de enfermeiros-líderes. Cogitare enferm. 2012;17(4):621-7.

10. Amestoy SC, Backes VMS, Thofehrn MB, Gue Martini J, Hörner BSM, Trindade LL. Percepção dos enfermeiros sobre o processo de ensino-aprendizagem na liderança. Texto Contexto Enferm. 2013;22(2):468-75.
11. Amestoy SC, Cestari ME, Thofehrn MB, Milbrath VM, Trindade LL, Backes VMS. Processo de formação de enfermeiros líderes. Rev. bras. enferm. 2010;63(6):940-5.

12. Minayo MCS. O desafio do conhecimento: pesquisa qualitativa em saúde. 12ª ed. São Paulo: Hucitec; 2010.

13. Kian KO, Matsuda LM, Waidmann MAP. Understanding the daily work of the nurse-leader. Rev Rene. 2011;12(4):724-31.

14. Dall'Agnol CM, Moura GMSS, Magalhães AMM, Falk MLR, Riboldi CO, Oliveira AP. Motivações, contradições e ambiguidades na liderança de enfermeiros em cargos de gestão em um hospital universitário. Rev. LatinoAm. Enfermagem. 2013;21(5):1172-8.

15. Araujo AC, Porto AR, Thofehrn MB, Lunardi VL, Silveira RS, Amestoy SC. Percepções de enfermeiros recém-formados sobre a prática de liderança no ambiente hospitalar. J Nurs Health. 2012;2(2):398-409.

16. Strapasson MR, Medeiros CRG. Liderança transformacional na enfermagem. Rev. bras. enferm. 2009;62(2):228-33.

17. Lorenzini E, Macedo TZ, Silva EF. Liderança na prática disciplinar de enfermagem: percepção de acadêmicos. Rev. enferm. UFPE. [Internet] 2013;7(7) [acesso em 30 out 2013]. Disponível:http://www.revista.ufpe.br/ revistaenfermagem/index.php/revista/pdf_2904 .

18. Fernandes U, Soares NV. Modelos de liderança adotados por enfermeiros de um hospital do Rio Grande do Sul. J Nurs Health. 2012;2(1):38-43

19. Lanzoni GMM, Meirelles BHS. Liderança do enfermeiro: uma revisão integrativa da literatura. Rev. Latino-Am. Enfermagem. 2011;19(3):651-8.

20. Rosa CMR, Fontana RT. A percepção de técnicos em enfermagem de uma unidade de terapia intensiva sobre a humanização no seu trabalho. Cienc. cuid. saude. 2010;9(4):752-9. 